\title{
Communication
}

\section{The Flotation Characteristics of Lignite After Low-Temperature Pyrolysis Pretreatment}

\author{
Yuexian Yu \\ School of Chemical and Environmental Engineering, China University of Mining and Technology (Beijing), Beijing, China \\ Email address: \\ yuyuexian2011@163.com

\section{To cite this article:} \\ Yuexian Yu. The Flotation Characteristics of Lignite After Low-Temperature Pyrolysis Pretreatment. International Journal of Oil, Gas and \\ Coal Engineering. Vol. 5, No. 4, 2017, pp. 59-62. doi: 10.11648/j.ogce.20170504.15
}

Received: February 1, 2017; Accepted: February 22, 2017; Published: October 23, 2017

\begin{abstract}
The basic property of the lignite and its pyrolysis products were studied by proximate and ultimate analysis. The effect of collector types on the flotation performance of semi-coke was studied. The results showed that collector consumption of semi-coke was much higher when compared with coking coals due to the larger surface area and a large amount of oxygen functional groups. The semi-coke exhibited a good flotation performance with the emulsified collector at an economical collector consumption.
\end{abstract}

Keywords: Lignite, Semi-Coke, Flotation, Emulsified Reagent, Surface Area

\section{Introduction}

In general, coal is classified according to its rank from anthracite to lignite. Usually, the inherent hydrophobicity declines with the decreasing rank of the coal. Flotation is widely used to treat the fine coal (usually $<0.5 \mathrm{~mm}$ ), which is based on the natural hydrophobicity of the coal. While due to the large amount of oxygen functional groups, most commonly, carboxyl, phenolic and carbonyl functionalities on the lignite surface, which reduce the hydrophobicity of the coal surface by increasing the number of sites that hydrogen bonds with water molecules, the lignite is very difficult to float [1]. A number of schemes have been carried out to improve the flotation performance of the lignite, for example, the hydrophobicity of hard-to-float lignite can be increased either by reduction of the oxygen functional groups at the coal surface before the treatment, or by the use of appropriate chemical agents. For example, the floatability of low rank coal was improved by heating the coal in the temperature range of $300-600^{\circ} \mathrm{C}[2]$. The addition of surfactants during the flotation process improved the ash/yield performance of the lignite and the overall performance of cationic surfactants was better [3]. Similar results were obtained by other researchers [4].

The aim of this work was to investigate the flotation performance of the lignite after low-temperature pyrolysis pretreatment $\left(500 \sim 600^{\circ} \mathrm{C}\right)$. The basic properties of the samples were studied by proximate and ultimate analysis. The flotation tests were carried out with various collectors such as diesel, kerosene, NE (a novel enhanced collector), combined reagents and emulsified reagents. And the underlying mechanisms were suggested based on results of the fourier transform infrared spectrometer (FTIR) and the surface area and pore size measurement.

\section{Experimental}

\subsection{Materials and Reagents}

The lignite and the pyrolysis products (semi-coke) which was heated in the temperature range of $500 \sim 600^{\circ} \mathrm{C}$ used in this study were taken from BRXL energy Ltd., Inner Mongolia, China. The samples were ground to $-0.5 \mathrm{~mm}$ which was suitable for the flotation by a laboratory roll mill $\varphi 12.7 \times 20 \mathrm{~cm}$.

Table 1. shows the size and ash distribution of the ground semi-coke. The ash content of each fraction was relatively close except the fraction of $-0.045 \mathrm{~mm}$ which contained more fine mineral matters. 
Table 1. Size and ash content analysis of the semi-coke.

\begin{tabular}{lllll}
\hline Size range, $\mathbf{m m}$ & yield, $\%$ & ash, $\%$ & Cum. yield, \% & Cum. ash, $\%$ \\
\hline+0.5 & 2.79 & 27.92 & 2.79 & 27.92 \\
$0.5-0.25$ & 20.32 & 26.07 & 23.11 & 26.29 \\
$0.25-0.125$ & 28.25 & 27.09 & 51.36 & 26.73 \\
$0.125-0.074$ & 15.46 & 28.28 & 66.82 & 27.09 \\
$0.074-0.045$ & 8.42 & 27.92 & 75.24 & 27.18 \\
-0.045 & 24.76 & 31.73 & 100.00 & 28.31 \\
Total & 100.00 & 28.31 & & \\
\hline
\end{tabular}

Table 2 shows the proximate and ultimate analysis of the sample. The fixed carbon content of the semi-coke increased from $37.71 \%$ to $63.20 \%$ and the volatile matter reduced from $37.20 \%$ to $7.21 \%$, at the same time, the elemental carbon content significantly increased from $44.76 \%$ to $64.61 \%$. It was indicated that the low-temperature pyrolysis treatment improved the quality of the lignite and upgraded the rank of the lignite sharply.

Table 2. Proximate and ultimate analysis of the sample, air dried.

\begin{tabular}{|c|c|c|c|c|c|c|c|c|}
\hline \multirow{2}{*}{ Sample } & \multicolumn{4}{|c|}{ Proximate analysis, \% } & \multicolumn{4}{|c|}{ Ultimate analysis, $\%$} \\
\hline & Moisture & Ash & Volatile matter & Fixed carbon & $\mathbf{C}$ & $\mathbf{H}$ & $\mathbf{N}$ & $\mathbf{S}$ \\
\hline Lignite & 16.06 & 28.20 & 37.20 & 37.71 & 44.76 & 4.59 & 0.82 & 0.74 \\
\hline Semi-coke & 3.27 & 29.64 & 7.21 & 63.20 & 64.61 & 0.84 & 0.91 & 0.39 \\
\hline
\end{tabular}

Diesel, kerosene, NE (a novel oil collector developed by CUMTB), combined reagents (Diesel $+\mathrm{NE}$, kerosene $+\mathrm{NE}$ ) and emulsified NE were used as collectors. The emulsified NE was prepared by high intensity shear and dispersed by ultrasonic treatment at a volume ratio of $\mathrm{NE}$, water and emulsifier 27:70:3 and 2-Octanol was used as the frother.

\subsection{Experimental Methods}

\subsubsection{Flotation Experiments}

Batch flotation tests were conducted in a laboratory XFD agitation flotation cell $(1.0 \mathrm{~L})$ at a constant impeller speed of $2100 \mathrm{r} / \mathrm{min}$ and air flow rate of $0.25 \mathrm{~m}^{3} / \mathrm{m}^{2} \cdot \mathrm{min}$. The pulp density and frother dosage was fixed at $80 \mathrm{~g} / \mathrm{L}$ and $0.1 \mathrm{~kg} / \mathrm{t}$. The flotation tests were carried out with diesel, kerosene, NE, diesel + NE, kerosene + NE, and emulsified NE, separately, the reagents were mixed with samples for a period of 2 minutes and then air was introduced into the cell, the froth products were collected for 3 minutes. After that, flotation concentrates and tailings were filtered, dried at $105^{\circ} \mathrm{C}$, and weighed. For the ash analysis, each product was mixed thoroughly and putted onto a clean steel plate and divided to about $5 \mathrm{~g}$ which was first ground using a mortar and pestle. Then, $1 \mathrm{~g}$ of each of the ground samples was burned in an oven at $815^{\circ} \mathrm{C}$ for $2.5 \mathrm{~h}$. The ash left over was weighed to calculate the ash content.

\subsubsection{Surface Area and Pore size Measurement}

The process of surface area and pore size measurement was determined by the automatic specific surface and pore size distribution analyzer (Autosorb-iQ2-MP, US). The adsorbate is nitrogen and bath temperature is $-195.8^{\circ} \mathrm{C}$, sample weight is $0.2694 \mathrm{~g}$. The whole measurement was automatically conducted by the instrument and the analysis result was calculated by the computer.

\subsubsection{Fourier Transform Infrared Spectroscopy (FTIR) Analysis}

The functional groups of the original lignite and the semi-coke were determined separately by fourier transform infrared spectrometer (Nicolet iS10, US). It was based on $\mathrm{KBr}$ squash technique and the ratio of the sample and $\mathrm{KBr}$ was $1: 160$. The wave number testing range is $4500 \sim 400 \mathrm{~cm}^{-1}$ with an interval of $1.929 \mathrm{~cm}^{-1}$, and the final results were collected as absorbance or transmittance.

\section{Results and Discussion}

\subsection{Contrast Test}

The flotation contrast tests between lignite and semi-coke were conducted under the same experiment conditions. The results are shown in Table 3.

Table 3. The results of the contrast test between lignite and semi-coke.

\begin{tabular}{llllllll}
\hline \multirow{2}{*}{ Sample } & Feed & \multicolumn{2}{l}{ Concentrate } & \multicolumn{2}{l}{ Tailings } & C. M. \\
\cline { 3 - 6 } & ash, \% & Yield, \% & Ash, \% & Yield, \% & Ash, \% & recovery, \% \\
\hline lignite & 22.83 & 20.44 & 20.00 & 79.56 & 23.56 & 21.20 \\
Semi-coke & 27.61 & 40.78 & 15.69 & 59.22 & 35.82 & 47.50 \\
\hline
\end{tabular}

As was shown in Table 3, the combustible matter (C. M.) recovery increased from $21.20 \%$ to $47.50 \%$, at the same time, the concentrate ash content decreased from $20.00 \%$ to $15.69 \%$. Therefore, after upgrading, the lignite was more floatable than before. It was evident that the low-temperature pyrolysis pretreatment improved the floatability of the lignite.

\subsection{Fourier Transform Infrared Spectroscopy (FTIR)}

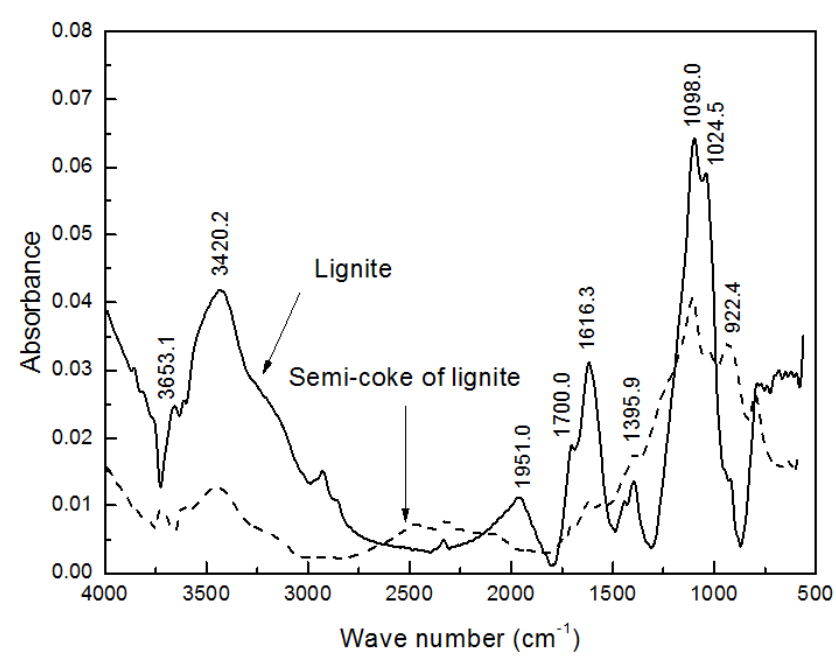

Figure 1. Comparison of FTIR between the lignite and semi-coke. 
As shown in Figure1, the solid-line curve represents the original lignite and the dash-line curve represents the semi-coke. $3653.1 \mathrm{~cm}^{-1}, \quad 3400 \sim 3500 \mathrm{~cm}^{-1} 1951.0 \mathrm{~cm}^{-1}$ $2780 \sim 2350 \mathrm{~cm}^{-1}$, and $1200 \sim 940 \mathrm{~cm}^{-1}$ correspond to the free hydroxyl, phenolic hydroxyl, alcohol hydroxyl, carboxyl, and hydroxyl C-O stretching groups, respectively [5-7]. These oxygen functional groups could strongly interact with water molecules and form hydrogen bonds in water, resulting in enhancement of the surface hydrophilicity of the semi-coke surface. The peak area of the infrared spectrum curve can reflect the amount of the functional groups, the larger the peak area, the higher the amount of the functional groups. As shown in Figure1, compared with the lignite, after upgrading, the amount of oxygen functional groups of the semi-coke significantly decreased, thus the floatability of the semi-coke was promoted, and this is consistent with the flotation results in Table 3.

\subsection{Flotation Experiments}

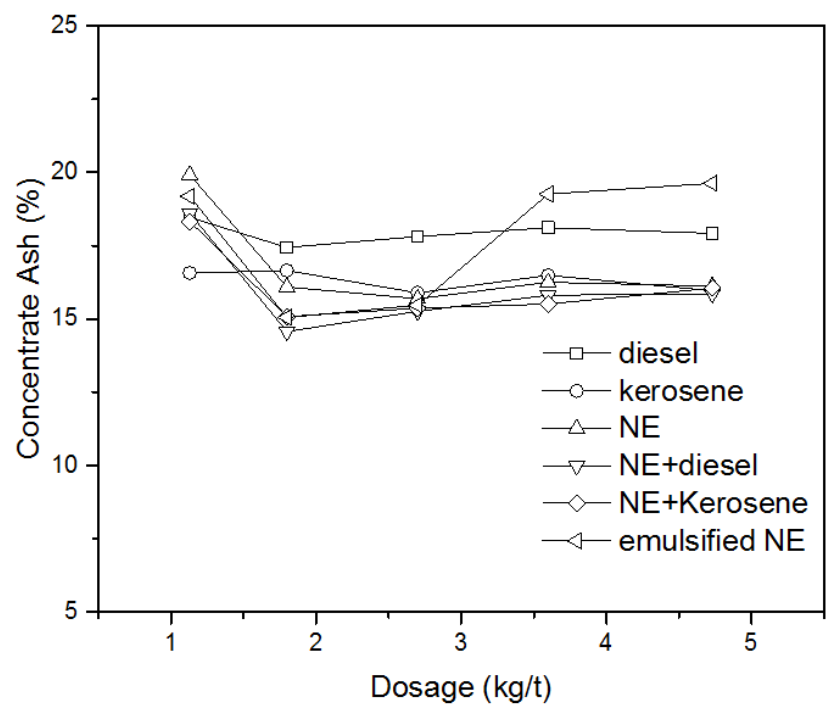

Figure 2. The ash content of the concentrate under different collector types.

Figure 2 shows the relationship between concentrate ash content and collector dosage at various collector types. The ash content of the concentrate fluctuated roughly in a range from $14.50 \%$ to $19.70 \%$. Compared with the feed ash $28.31 \%$, the flotation operation beneficiated the semi-coke and discarded a portion of mineral impurities. However, the separation efficiency of the semi-coke was not good as that of the bituminous coal which usually exhibited a high beneficiation performance. As shown in Figure2, with the increase of the collector consumption, the similar trend was observed for the ash content of the concentrate. When the collector dosage was very low (about $1 \mathrm{~kg} / \mathrm{t}$ ), the concentrate ash content was relatively higher than other collector dosages. However, when the collector dosage increased gradually, the concentrate ash content decreased and leveled off at the final. In addition, the concentrate ash content using emulsified NE went up at the last two points of the curve, this was because the composite coal-gangue particles were floated into the froth products due to the excessively emulsified NE.

The ash content of the concentrate at the first point on the curve in Figure2 was comparatively high. The main reason for this was the initial collector dosage was too low to improve the surface hydrophobicity of the semi-coke, thus, the difference between the surface hydrophobicity of the organic matter and mineral matter was very small. In addition, the foam layer was very thin, therefore, many mineral impurities suspended in the slurry were scraped into the concentrate, resulting in a high ash content of the concentrate. However, with the increase of the collector dosage, the concentrate ash content decreased, which indicated that the collector began to take effect.

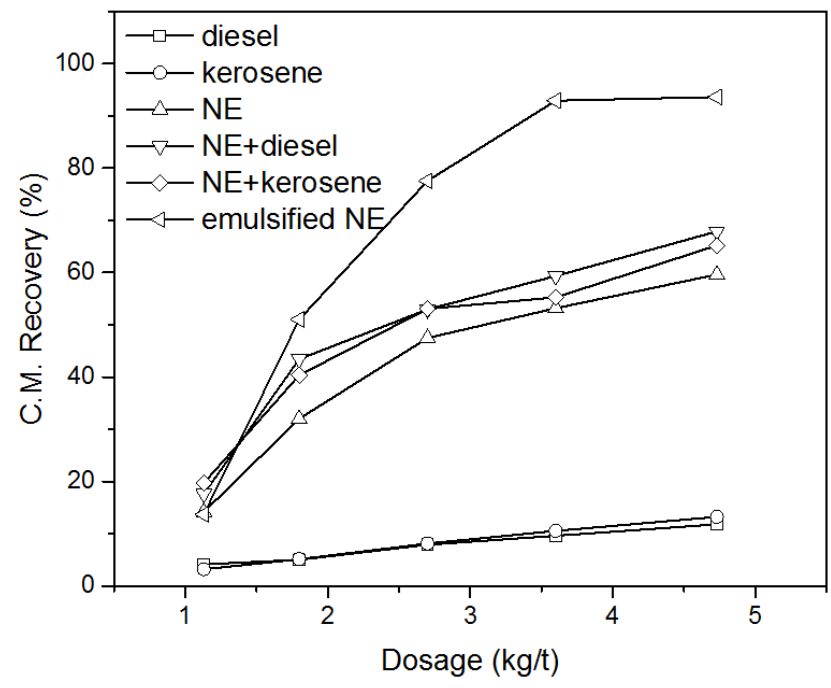

Figure 3. The combustible matter recovery of the concentrate under various collectors.

As can be seen from Figure 3, the combustible matter recovery of the concentrate rose rapidly with the increasing collector dosage. Compared with other collectors, the diesel and kerosene failed to collect the semi-coke effectively with only less than $20 \%$ C. M. recovery at $5 \mathrm{~kg} / \mathrm{t}$ dosage. Obviously, The NE collector has a better collecting ability than diesel or kerosene, this is because the NE contains many long chain alkanes, olefins and aromatic substances (such as benzene, naphthalene, etc.). In addition, it contains some polar materials, such as acid amine. Adsorption on the coal surface of long chain alkane, enhancing the surface hydrophobicity of coal particles, and at the same time, aromatic substances are prone to adsorb on the aromatic structure of semi-coke particle surface, producing strong hydrogen bonding adsorption with the oxygen functional groups on semi-coke particle surface. Therefore, the NE enhanced the hydrophobicity of semi-coke, promoted the efficiency of the flotation and induced a higher flotation recovery.

The flotation recovery with combined reagents (Diesel + $\mathrm{NE}$, kerosene $+\mathrm{NE}$ ) was better than mono reagents. It was indicated from Figure2 and Figure 3 that with the combined reagents, the concentrate ash content was lower but the C. M. recovery was larger than that of the single reagents. This 
demonstrated that the combined reagents have a better selectivity and a stronger collecting ability for the semi-coke.

As shown in Figure 3, the emulsified NE greatly promoted the floatability of the semi-coke and produced a much higher combustible matter recovery. For example, when the dosage of emulsified NE was $2.70 \mathrm{~kg} / \mathrm{t}$, the C. M. recovery and ash content of the concentrate was $77.56 \%$ and $15.47 \%$, respectively. Literatures reported that the emulsification of kerosene by high intensity stirring produced droplets with a diameter of $\sim 20 \mu \mathrm{m}$, while emulsification with addition of surfactants (anionic and cationic) reduced the droplet size to about $1.5 \sim 2 \mu \mathrm{m}[8,9]$. Therefore, the number of droplets in the unit volume pulp increased significantly at the same dosage of collectors and the collision probability between particles and collector droplets increased vastly, thus the flotation recovery improved. Therefore, from the results of this present work, it is demonstrated that the reagent emulsification is an effective and economical approach to beneficiate the difficult-to-float semi-coke. However, the reagent consumption of semi-coke is much higher when compared with the coking coal.

\subsection{Surface Area and Pore size Distribution}

The surface area and pore size distribution was shown in Table 4. Total pore volume of the semi-coke was $5.685 \times 10^{-2}$ cc/g for pores smaller than $324.1 \mathrm{~nm}$ (Diameter) at $\mathrm{P} / \mathrm{P}_{0}=$ 0.99406 . The average pore diameter was $18.4241 \mathrm{~nm}$. The multi-point BET method showed that the surface area of the semi-coke was $12.343 \mathrm{~m}^{2} / \mathrm{g}$, however, the surface area of coking coal was usually about 2 to $5 \mathrm{~m}^{2} / \mathrm{g}$ [10], therefore, obviously the large surface area of the semi-coke surface is the key factor for the large reagent consumption.

Table 4. Surface area and pore size distribution of the semi-coke.

\begin{tabular}{|c|c|c|c|c|}
\hline \multicolumn{5}{|l|}{ BET summary } \\
\hline Slope & Intercept & Correlation coefficient, $R$ & C constant & Surface area, $\mathrm{m}^{2} / \mathrm{g}$ \\
\hline 281.79 & 0.3693 & 0.9994 & 764.115 & 12.343 \\
\hline \multicolumn{5}{|l|}{ BJH adsorption summary } \\
\hline Surface area, $\mathrm{m}^{2} / \mathrm{g}$ & & Pore Volume, cc/g & \multicolumn{2}{|c|}{ Pore Diameter Dv(d), nm } \\
\hline 7 & & 0.054 & 3.055 & \\
\hline \multicolumn{5}{|l|}{ Average Pore Size summary } \\
\hline Average pore Diameter, nm & & 18.4241 & & \\
\hline
\end{tabular}

\section{Conclusion}

The floatability of the lignite was improved after the low-temperature pyrolysis pretreatment due to the reduction of the hydrophilic functional groups. However, the collector consumption of semi-coke was still higher compared with the coking coals due to the large surface area of the semi-coke. In addition, the regular oil collector failed to float the semi-coke. However, the emulsified NE collector dramatically increased the C. M. recovery and obtained an acceptable concentrate ash content at economical reagent consumption.

\section{Acknowledgments}

Financial support to the project was the supported by National Natural Science Foundation of China (NO. 51604280) for which the authors express their appreciation.

\section{References}

[1] Cebeci Y. The investigation of the floatability improvement of Yozgat Ayridam lignite using various collectors. FUEL. 2002; 81: 281-289.

[2] Ateşok G, Celik MS. A new flotation scheme for a difficult-to-float coal using pitch additive in dry grinding. FUEL. 2000; 79: 1509-1513.
[3] Vamvuka D, Agridiotis V. The effect of chemical reagents on lignite flotation. INT J MINER PROCESS. 2001; 61: 209-224.

[4] Jia R, Harris GH, Fuerstenau DW. An improved class of universal collectors for the flotation of oxidized and/or low-rank coal. INT J MINER PROCESS. 2000; 58: 99-118.

[5] Cao W, Cao W, Peng Y, Qiu S, Miao N, Pan F. Experimental study on the combustion sensitivity parameters and pre-combusted changes in functional groups of lignite coal dust. POWDER TECHNOL. 2015; 283: 512-518.

[6] Liu J, Wu J, Zhu J, Wang Z, Zhou J, Cen K. Removal of oxygen functional groups in lignite by hydrothermal dewatering: An experimental and DFT study. FUEL. 2016; 178: 85-92.

[7] Zhang Y, Jing X, Jing K, Chang L, Bao W. Study on the pore structure and oxygen-containing functional groups devoting to the hydrophilic force of dewatered lignite. APPL SURF SCI. 2015; 324: 90-98.

[8] Bouchemal K, Briançon S, Perrier E, Fessi H. Nano-emulsion formulation using spontaneous emulsification: solvent, oil and surfactant optimisation. INT J PHARMACEUT. 2004; 280 : 241-51.

[9] Gelot A, Friesen W, Hamza HA. Emulsification of oil and water in the presence of finely divided solids and surface-active agents. Colloids and surfaces. 1984; 12: 271-303.

[10] Linge HG. The surface area of coal particles. FUEL. 1989; 68: 111-113. 